\title{
Representações sociais do trabalho para assistidos do sistema penitenciário cearense
}

\author{
Social representations of labor for assisted of prison system of Ceará \\ Representaciones sociales del trabajo para asistentes del sistema penitenciario cearense
}

Recebido: 16/07/2021 | Revisado: 25/07/2021 | Aceito: 30/07/2021 | Publicado: 05/08/2021

\author{
Ana Priscila Barroso Araújo \\ ORCID: https://orcid.org/0000-0002-8826-7302 \\ Faculdade Uninta Itapipoca, Brasil \\ E-mail: anapriscila_araujo@yahoo.com.br \\ Luciana Maria Maia Viana \\ ORCID: https://orcid.org/0000-0003-1491-5685 \\ Universidade de Fortaleza, Brasil \\ E-mail: lumariamaia@hotmail.com
}

\begin{abstract}
Resumo
Conhecer as representações sociais do trabalho para assistidos do sistema penitenciário cearense, suas formas de inserção e expectativas em relação aos contextos de trabalho foi o objetivo dessa pesquisa. Participaram 23 assistidos, residentes em Fortaleza, que participam de um programa de inserção profissional para egressos do sistema prisional em um órgão público do Ceará. Os dados foram coletados por meio de entrevistas semiestruturadas e submetidos à análise de conteúdo. Os resultados evidenciaram o trabalho como condição necessária para a liberdade (material, pessoal/afetiva e social), bem como para a construção de uma nova sociabilidade. Também foram observados aspectos que dificultam o processo de participação dos assistidos do sistema penitenciário no mercado de trabalho, tais como barreiras pessoais e sociais. Conclui-se que as representações sociais orientam práticas e estratégias sociais, refletindo as normas das instituições sociais ou as ideologias relacionadas ao lugar que os assistidos ocupam na sociedade.
\end{abstract}

Palavras-chave: Assistidos do sistema penitenciário; Representações sociais; Mercado de trabalho.

\begin{abstract}
To know the social representations of the work for the assistants of the prison system of Ceará, its forms of insertion and expectations in relation to the work contexts was the objective of this research. Twenty-three assistants, who were residents of Fortaleza, participated in the work of the Secretariat of Justice and Citizenship of the State of Ceará (Sejus). Data were collected through semi-structured interviews and submitted to content analysis. The results evidenced work as a necessary condition for freedom (material, personal / affective and social), as well as for the construction of a new sociability. Emphasis is given to aspects that make it difficult for the prison system to participate in the labor market, such as personal and social barriers. It is concluded that social representations guide social practices and strategies, reflecting the norms of social institutions or the ideologies related to the place that the assistants occupy in society.
\end{abstract}

Keywords: Prison system assisted; Social representations; Job market.

\begin{abstract}
Resumen
Conocer las representaciones sociales del trabajo para asistidos del sistema penitenciario cearense, sus formas de inserción y expectativas en relación a los contextos de trabajo fue el objetivo de esa investigación. Participaron 23 asistentes, residentes en Fortaleza, que participan en un programa de inserción profesional para egresados del sistema penitenciario en un órgano público de Ceará. Los datos fueron recolectados por medio de entrevistas semiestructuradas y sometidas al análisis de contenido. Los resultados evidenciaron el trabajo como condición necesaria para la libertad (material, personal / afectivo y social), así como para la construcción de una nueva sociabilidad. También se observaron aspectos que dificultan el proceso de participación de los asistentes del sistema penitenciario en el mercado de trabajo, tales como barreras personales y sociales. Se concluye que las representaciones sociales orientan prácticas y estrategias sociales, reflejando las normas de las instituciones sociales o las ideologías relacionadas con el lugar que los asistidos ocupan en la sociedad.
\end{abstract}

Palabras clave: Asistidos del sistema penitenciario; Representaciones sociales; Mercado de trabajo.

\section{Introdução}

A violência é um fenômeno complexo, aspecto que pode ser evidenciado quando se considera a discussão que circunda o tema e a grande variedade de sentidos que assume. Pode se expressar em diversos contextos e modalidades, afetar 
os indivíduos em qualquer etapa do seu ciclo vital e provocar inúmeras consequências (Santos \& Rosenburg, 2014). No que se refere a pessoas que passaram pelo sistema prisional, é comum identificá-las apenas como atores da violência, sem levar em consideração que suas histórias de vida antes, durante e após o aprisionamento são marcadas também pela existência da violência, seja na dimensão física ou simbólica. Desse modo, a criminalidade tem sido sistematicamente associada a uma camada da população, estratos sociais em desvantagens, sem considerar a condição de exclusão que vivenciam esses indivíduos, marcada pelas dificuldades de acesso, de inclusão e de garantia a recursos como educação, trabalho e saúde (CNJ, 2014).

No que se refere ao acesso ao trabalho, Coimbra (2001) afirma que a marginalização impiedosa dos "excluídos do trabalho" responsabiliza os próprios desempregados pela perda e/ou dificuldade de conseguir alguma colocação no mercado. A autora aponta que esses marginalizados são levados a se considerar indignos da sociedade e, sobretudo, responsáveis pela sua própria situação de vulnerabilidade. Assim, a condição de exclusão na qual milhões de pessoas estão sendo colocadas tem gerado mais medo e insegurança, sem dúvida, mais violência para os desassistidos.

A título de esclarecimento, parte-se da premissa de que o trabalho, seja na forma de qualificação profissional ou de ingresso no mercado formal ou informal, constitui uma das principais formas de enfrentamento da problemática da exclusão social. O trabalho, como apontado por diferentes autores (Bernal, 2010; Medina, 1977), é importante meio de participação social nas sociedades capitalistas. As pessoas se autoavaliam, são avaliadas e julgadas tendo em vista o trabalho que desenvolvem e o significado social e simbólico das atividades que desempenham (Salanova, Gracia, \& Peiró, 1996).

De forma específica, no contexto penitenciário, o trabalho é compreendido como possibilidade de reabilitação e reinserção social de indivíduos, tendo em vista que pode proporcionar a requalificação do "ladrão" em operário dócil. É por meio do trabalho que se distinguem todos os homens de bem; e é por meio dele também que se organiza a vida, as atividades e os relacionamentos sociais e afetivos (Souza, 2009).

Embora existam essas iniciativas institucionais, é importante notar que a condição de ter sido condenado, estar preso ou ter estado em uma prisão permanece um forte estigma que, independentemente do crime e de condições sociais diversas que marcam a vivência desse indivíduo, conduz à ideia globalizante de criminoso, perigoso, de ameaça à sociedade (Seron, 2009), comprometendo sobremaneira a participação desses sujeitos em contextos de trabalho, da mesma forma que diminui suas possibilidades de realização afetiva, educacional e política. É importante destacar que esses aspectos participam diretamente da construção da identidade desses sujeitos, que tecem uma visão sobre si mesmos, sobre o trabalho e as possibilidades de inserção no mercado de trabalho a partir dessas imagens socialmente compartilhadas sobre eles e suas capacidades de participação laboral e social (Jacques, 1997).

Essas imagens podem ser abordadas na Psicologia Social a partir das Representações Sociais, descritas como um sistema de valores, ideias e práticas originadas na vida cotidiana no curso de comunicações interpessoais, que têm, entre suas funções, orientar as pessoas em seu mundo material e social (Moscovici, 2010). Desse modo, de forma controlada ou automática, consciente ou não, a maioria dos comportamentos das pessoas está relacionada às suas representações sociais (Vala, 2002). As representações sociais também possibilitam às pessoas justificar suas opiniões e ações numa dada situação (Abric, 1994).

Desse modo, as representações sociais compartilhadas sobre o trabalho são distintas, considerando-se os diferentes grupos sociais. No caso de pessoas que fazem parte do sistema penitenciário, as representações sociais sobre o trabalho são construídas e compartilhadas tendo em vista a pertença grupal, as ideias socialmente compartilhadas e as experiências (ou não) desses indivíduos em contextos de trabalho e de inserção no mercado de trabalho.

Nesse sentido, propõe-se como objetivo geral desta dissertação conhecer as representações sociais do trabalho para assistidos do sistema penitenciário cearense, considerando que ajudam a compreender as formas de inserção, estratégias e 
expectativas desse grupo em contextos de trabalho, uma vez que as representações preparam para a ação, seja conduzindo para o comportamento, seja modificando e reconstruindo os elementos do meio ambiente no qual o comportamento deve ter lugar.

\section{Metodologia}

Este estudo constitui uma pesquisa descritiva, desenvolvida a partir de uma abordagem qualitativa, cujos dados foram coletados em campo (Bauer \& Gaskell). Os procedimentos que norteiam o seu desenvolvimento são detalhados a seguir.

\section{Participantes:}

Os participantes desta pesquisa são 23 assistidos, sendo 15 homens e 8 mulheres, residentes em Fortaleza, que participam de um programa de inserção profissional para egressos do sistema prisional em um órgão público do Ceará. A idade média dos participantes é de 30 anos, variando de 22 a 65 anos.

Entre as experiências profissionais declaradas pelos assistidos tem-se: serviços gerais, serviços domésticos, atividades no comércio informal, atividades na construção civil, destacando-se atividades relacionadas à limpeza.

A trajetória profissional e as ocupações desenvolvidas pelos assistidos sugerem uma realidade de baixa escolaridade e pouca qualificação profissional, assim como de ocupação em atividades precarizadas e de inserção em contextos informais de trabalho.

\section{Instrumento, coleta e análise dos dados:}

Os dados foram coletados por meio de entrevistas conduzida com roteiro semiestruturado. As questões da entrevista foram divididas em três eixos temáticos: concepções acerca do trabalho; formas de inserção em contextos de trabalho; e expectativas de inserção no mercado trabalho.

Foi solicitada por escrito autorização da instituição em que os assistidos trabalhavam para a realização da pesquisa. Todas as entrevistas foram realizadas pela pesquisadora responsável e ocorreram no próprio local de trabalho dos participantes, com duração média de cinquenta minutos. As entrevistas foram gravadas com o consentimento dos participantes e posteriormente transcritas. Nenhum dos sujeitos habilitados para participação na pesquisa se recusou a participar da mesma.

Após a transcrição das entrevistas, procedeu-se à leitura do material, utilizando a técnica de análise de conteúdo (Bardin, 2010). A organização dos dados se iniciou com a leitura flutuante das entrevistas e a identificação preliminar dos principais núcleos de sentido (temas) mencionados como respostas às questões. Da análise temática conduziu-se e discutiu-se neste estudo as seguintes categorias: concepções acerca do trabalho; formas de inserção em contextos de trabalho; e expectativas de inserção no mercado trabalho.

\section{Resultados e Discussão}

Os resultados serão apresentados e discutidos seguindo os eixos temáticos que conduziram as entrevistas.

\section{Concepções acerca do trabalho}

Considerando a discussão atual acerca da centralidade do trabalho no mundo ocidental contemporâneo (Bernal, 2010; Medeiros \& Macedo, 2006; Navarro \& Padilha, 2007), perguntou-se o que os participantes pensam sobre o trabalho. Importante mencionar que o trabalho no sistema penitenciário tem a finalidade de promover a inclusão social prevista na Lei de Execução Penal (LEP). Se por um lado, o trabalho tem sido considerado uma categoria central e, do ponto de vista jurídico, um meio de ressocialização de apenados; por outro, as estatísticas denunciam um mercado de trabalho excludente 
caracterizado por preconceitos e falta de oportunidades, especialmente para membros de determinadas categorias sociais, que experimentam uma condição de exclusão social e se encontram à margem da sociedade.

Como poderá ser percebido, essa tensão que constitui o trabalho para esse grupo aparece nas respostas dos participantes, para os quais o trabalho é apresentado tanto como importante instrumento promotor de inclusão social, como forma de exploração e exclusão social. A análise desses dados revelou que os assistidos tenderam a conceituar o trabalho como condição chave para a sua manutenção longe das grades, para se reinserir e para se sentir cidadãos. No caso deles, a saída da prisão e a busca de trabalho é pautada pela crença na reinserção pelo trabalho.

A ideologia que está em jogo no sistema penitenciário é em muito determinada pela centralidade do trabalho (Madeira, 2008). Em decorrência de discursos judiciais, prisionais, científicos, religiosos e populares, o trabalho, no imaginário dos assistidos, é a saída para passarem a viver de acordo com as regras sociais, como trabalhadores (Bussinguer, 2013; Cardoso, 2006; Julião, 2009; Madeira, 2008; Sampaio, 2008; Seron, 2009; Souza, 2007). Neste sentido, as representações se constituem a partir de crenças, consolidadas historicamente com a constituição advinda do capitalismo industrial, que defendem o trabalho como solução para os problemas econômicos e psíquicos (Navarro \& Padilha, 2007), bem como para a saída do crime (Madeira, 2008). Nesta pesquisa, o retorno financeiro e a luta pela sobrevivência foram utilizados fortemente para expressar a visão dos assistidos acerca do trabalho.

Através do trabalho que consigo é sobreviver: eu, meu filho e minha esposa, entendeu? É daí onde eu tiro o alimento, o sustento de cada dia, o pão de cada dia que eu levo para casa. (part_15)

Os assistidos citaram a ideia de saída do tédio, da imobilidade e do ganho da pena. O provérbio popular "mente vazia é oficina do diabo", utilizado por um dos participantes da pesquisa, ilustra a ideia de que o trabalho tem possibilitado a ocupação e a medida correta contra os desvios de sua imaginação, pensamentos e ações relacionadas à reincidência criminosa (Barros, 2009; Lemos et al., 1998; Toledo et al., 2014).

Porque quando você assume um trabalho. . e e tira da sua mente aquilo tudo que já aconteceu no passado. (part_23)

O trabalho também apareceu como possibilidade de aperfeiçoamento profissional/ realização pessoal, destacando-se a necessidade de aprimorar os conhecimentos para alcançar vitória. Dessa forma, houve, ao mesmo tempo, pontos de aproximação entre as concepções adotadas pelos assistidos investigados e o saber especializado contemporâneo. Esse saber enumera as vantagens do trabalho, pois o aprendizado ou aperfeiçoamento de uma profissão poderia ajudar o egresso na sua reintegração. Tais fatos podem ser percebidos nas falas dos assistidos que consideram a realização do trabalho como pontoschave para a realização pessoal, ou seja, para a realização de expectativas de consumo.

Trabalho é o meio de aprimorar mais meu conhecimento e conquistar vitória. (part_23)

O trabalho assumiu outra característica na concepção dos entrevistados: a de exploração. Conforme o discurso de uma entrevistada, o trabalho assume um lugar escravizador na vida das pessoas, atendendo às expectativas de consumo/do capitalismo. A participante completa a sua crítica dizendo que o trabalho não está ligado à realização pessoal. Essa fala leva à reflexão sobre a efetividade do trabalho (Madeira, 2008; Souza et al., 2016; Tomé, 2011). 
O trabalho não era para ser o que ele é. O trabalho não era para ser uma coisa que consumisse um terço da vida do ser humano. O trabalho era para ser algo que garantisse que a gente tivesse uma vida que bastasse. Eu vejo o trabalho como algo escravizador, embora eu goste do meu trabalho, eu vejo que o trabalho não tá ligado a uma realização pessoal, o trabalho tá ligado a você ter, ter, ter, tanto que você acaba se tornando escravo do seu trabalho. (part_19)

Em relação a essa questão, alguns estudos corroboram essa reflexão dizendo que o trabalho para essas pessoas tende para as atividades braçais, pouco valorizadas no contexto produtivo, sem que represente alguma fonte de prazer, sem falar de quando garante precariamente a sobrevivência. No caso dos assistidos, o trabalho é muito citado como meio de se inserirem, de se sentirem cidadãos, de sobrevivência e de mudança de vida. Entretanto, foi possível identificar nas falas dos entrevistados pontos de tensão, que indicaram que o trabalho tem sempre um significado - positivo ou negativo, a depender da forma como está exposto para o indivíduo (Barbalho \& Barros, 2010; Seron, 2009).

\section{Concepções acerca da inserção em contextos de trabalho}

Buscando conhecer as concepções sobre a inserção em contextos de trabalho, os assistidos tenderam a conceituar o trabalho desenvolvido descrevendo suas práticas laborais cotidianas. Pode-se pensar que falar o que fazem no dia a dia de trabalho possibilita-lhes assumir um trabalho / uma rotina que integra as exigências cotidianas do cidadão (pontualidade, assiduidade, disciplina, responsabilidade), bem como mostra um bom desempenho e restabelece as rotinas e regras do mundo do trabalho, há muito perdidas pelo tempo que passaram presos e pelas dificuldades encontradas na vida (Madeira, 2008; Seron, 2009). Contudo, às vezes esse dia a dia é uma tarefa penosa para os assistidos, pois em suas falas sugerem condições desfavoráveis de trabalho, que podem estar ligadas à execução das tarefas / práticas de trabalho (Seron, 2009) e à realização de um trabalho no qual falta sentido.

Às vezes todo dia pela manhã a gente acorda, trabalha de novo, eu tenho que chegar naquele canto de novo, eu creio que aquilo se torna como se fosse um fardo, né? De estresse, cansaço, de fadiga. (part_8)

Os assistidos, quando se reportam ao trabalho desenvolvido, o consideram de maneira positiva. Esse resultado parece estar em consonância com o encontrado por Esteban et al. (2014), que indica também que o trabalho é apenas um primeiro passo necessário para a melhoria das condições de vida de muitos. Essa visão leva em consideração as relações interpessoais, a oportunidade de desenvolver um trabalho e o dia a dia de trabalho dos entrevistados.

Nesta pesquisa, os entrevistados revelam a ideia de que as relações interpessoais, entre pares e/ou com superiores, são aspectos importantes para o trabalho que desenvolvem. De acordo com Madeira (2008), os programas de apoio por meio do trabalho se dão também a partir do desenvolvimento de relações interpessoais. O que, de acordo com Seron (2009), significa que o trabalho, de maneira geral, consiste na capacidade de estabelecer relações interpessoais entre trabalhadores de um mesmo contexto, tornando possível, por sua vez, estimular a integração social dos membros de uma mesma comunidade profissional.

É porque todo mundo aqui é amigo, todo mundo aqui é companheiro, porque o trabalho sem amigo não é nada. (part_5) 
No caso dos assistidos, pode-se constatar que identificam muitas dificuldades no trabalho realizado, seja pela atividade desenvolvida, seja pelas relações interpessoais estabelecidas, as condições de trabalho e a falta de direitos. Alguns entrevistados afirmaram que queriam fazer outra coisa, que as relações interpessoais eram carregadas de estresse e que a má qualidade da alimentação, a falta de material de trabalho, a falta de horário de descanso, o excesso de trabalho, a falta de benefícios, o baixo salário e a falta de vínculo empregatício, bem como a falta de emprego / oportunidade de trabalho representam condições desfavoráveis de trabalho que corroboram a ineficácia da inserção dos assistidos em contextos de trabalho.

\section{O que menos gosto é da comida. É igual da cadeia. Falta de material. (part_11)}

Os assistidos afirmam que as atividades que desempenham colaboram para as oportunidades de aprendizagem. A esse respeito, Moki (2005) comenta que as mulheres encarceradas compartilharam da opinião que usarão a aprendizagem do trabalho carcerário quando estiverem em liberdade, pois acreditam que o trabalho seja capaz de profissionalizá-las, visando sua reintegração à sociedade. Nesse sentido, Tomé (2011) considera que os apenados imbuídos de algum tipo de aprendizado e com vontade de viver a vida podem experimentar o retorno ao meio social mediante a obtenção de trabalho e renda própria, bem como de um novo espaço relacional.

Eu tô aprendendo muito aqui, as coisas que eu não fazia, aí tão me ensinando. (part_4)

Algumas respostas dos assistidos demonstraram que o trabalho desempenhado pode lhes proporcionar valorização pessoal e prestígio. Esse achado vai na direção do resultado encontrado por Lemos et al. (1998), que indica que o trabalho penitenciário tem se organizado de maneira que as tarefas realizadas não representem apenas estímulos mecânicos, mas que, acima de tudo, possibilitem aos apenados encontrar nas condições de trabalho os fatores necessários ao seu crescimento pessoal. Esses resultados confirmam aqueles obtidos por Lopes et al. (2016), de que o trabalho representa a esperança de conseguir reconstruir a vida no seu retorno ao meio social, o resgate da confiança em si mesmo, a melhora de sua autoestima diante dos familiares, pares, superiores e sociedade.

Confiam muito na minha pessoa para tudo. (part_20)

Há respostas também que manifestem posicionamento favorável a esse crescimento pessoal, contudo emitem críticas e destacam o preconceito e a discriminação como aspectos presentes em seus ambientes de trabalho, dificultando os seus desenvolvimentos profissionais e pessoais.

Sobre o preconceito e a discriminação, pode-se supor que muitas vezes impedem a inserção desses indivíduos no mercado de trabalho (Lopes et al., 2016). As autoras mencionaram que a sociedade é resistente à contratação desses indivíduos, o que intimida as organizações a contratarem esse tipo de mão de obra. Ainda sobre essa questão, de acordo com Rocha et al. (2013), as organizações estão ofertando vagas que não são preenchidas e as justificativas são a falta de qualificação dos candidatos e a documentação exigida na contratação. Contudo, as verdadeiras razões encontram-se no preconceito contra esses indivíduos, socialmente reforçado e reproduzido na dinâmica das organizações de trabalho.

O preconceito ainda existe, é muito difícil. A maior hipocrisia é dizer que o preconceito não existe, mas sempre vai existir. Até mesmo nessas células daqui, que é para ajudar, tem. Sempre vai existir. (part_7) 
É importante notar que, de acordo com alguns entrevistados, o trabalho desempenhado é também uma forma de organizar o tempo e a mente, como já salientado na primeira dimensão investigada.

\section{Mente vazia é oficina do diabo, né? Ocupa a mente. (part_11)}

O trabalho é concebido como um meio de efetivação de direitos e, como foi visto nos resultados, o acesso a ele permitiu à entrevistada viver os direitos humanos na prática, considerando a sua inserção atual.

Diante do exposto, pode-se concluir que os assistidos do sistema penitenciário assumem, enquanto grupo minoritário, o discurso da classe dominante. Nesse sentido, pode-se dizer que as representações que os participantes têm das condições de seu desenvolvimento no trabalho são construídas nas relações assimétricas com o grupo dominante. Contudo, percebe-se que as representações dos entrevistados também são construídas a partir do seu grupo de pertença. Isto parece ficar claro quando criticam as condições de trabalho e os aspectos que dificultam a inserção deles nesse mercado. Vale salientar que as diferenças nos discursos dos participantes nesta segunda dimensão ganham mais destaque quando analisadas em conjunto com a terceira dimensão investigada.

\section{Concepções acerca das expectativas de inserção no mercado de trabalho}

Os participantes, quando solicitados a falar sobre suas expectativas de inserção no mercado de trabalho, se referiam, em suas respostas, na grande maioria das vezes, à esperança na criação de novas oportunidades de trabalho e à manutenção da atividade que desenvolvem.

A análise dos dados revelou que à esperança na criação de novas oportunidades de trabalho sugere aspirações de mudança pessoal e material, bem como sonho em relação a sua vida futura e seu futuro profissional. Os participantes se percebem como futuros empreendedores, na condição financeira, na constituição da família, no desenvolvimento profissional e no desenvolvimento de atividade junto aos apenados como forma de contribuição social. Esse achado vai na direção do resultado encontrado por Lemos et al. (1998), indicando que os apenados acreditam que o trabalho consiste em meio para adquirirem uma nova postura diante do mundo e, dessa forma, virem a ser aceitos pela sociedade. Está presente a crença de que o trabalho pode realmente gerar condições para se estruturarem socialmente. Esses resultados confirmam aqueles obtidos por Madeira (2008), segundo o qual os egressos mais novos e que passaram menos tempo na prisão cultuam expectativas altas com relação às suas trajetórias de vida, uma vez que o status social está completamente atrelado a sua inserção em contextos de trabalho e à posição obtida por intermédio dessa inserção.

Eu gosto dessa área de auxiliar administrativo, né? Futuramente, eu penso em fazer uma faculdade de administração, só falta eu terminar meu terceiro ano do ensino médio. Eu creio que o Senhor vai me dar condições para eu fazer a faculdade e me formar. (p_8)

Sobre à manutenção da atividade que desenvolvem, sugere-se conhecimento, gosto e permanência quanto às chances de melhorias futuras na vida pessoal e profissional, bem como de resignação, uma vez que suas histórias de vida pessoal e profissional são caracterizadas pela exploração e opressão. Na mesma direção, os achados de Seron (2009) indicam que os egressos não possuem grande perspectiva de ascensão profissional, porquanto os trabalhos desempenhados, em sua maioria, não fazem parte de nenhum tipo de carreira profissional. Nessa circunstância, de acordo com Madeira (2008), em termos de esperanças e oportunidades, os egressos mantêm-se fiéis às possibilidades objetivas, não almejando mais do que sua condição 
real de vida e de ex-presidiário pode lhes proporcionar. De acordo com Lemos et al. (1998), os apenados percebem que a maneira como o trabalho penitenciário se desenvolve não contribuirá para a sua realização.

Rapaz, as coisas, eu sou pai de quatro filhos. O que vier para mim, não tem como eu exigir muito não. (p_20)

É importante esclarecer que mesmo quando os participantes apresentaram discursos que se enquadraram na categoria esperança na criação de novas oportunidades de trabalho, como o de que almejam obter um trabalho melhor, a grande maioria não demonstrou grandes esperanças, uma vez que podem ser frustradas pelas inserções temporárias de trabalho, bem como pela falta de carteira assinada e a desqualificação profissional do assistido.

Alguns trechos assinalados nesta dimensão sugerem algumas críticas que os assistidos fazem acerca de suas realidades, nas quais indicam as poucas chances de obtenção de algum trabalho, bem como de crescimento profissional.

\section{Considerações Finais}

A pesquisa permitiu evidenciar que os egressos do sistema prisional enfrentam diversos desafios no seu retorno à sociedade, a maioria atrelada ao estigma com o qual a segregação para cumprimento da lei penal marca esses indivíduos, tornando-os vulneráveis à reincidência, porquanto dificulta sua reinserção social.

Os resultados obtidos evidenciaram o trabalho como meio de se inserirem, de se sentirem cidadãos, de sobreviverem e de mudarem de vida, embora fosse também concebido em um viés negativo, a depender da forma como é exposto para o indivíduo. Quanto às formas de inserção em contextos de trabalho, consideraram-nas oportunidades de aprendizagem, valorização e reconhecimento, sem, contudo, afastarem de cada uma as dificuldades que consideram serem a elas inerentes, a exemplo das condições em que as atividades laborais se realizam e, principalmente, das relações assimétricas construídas nesses contextos, a destacar o preconceito e a discriminação. Em relação às expectativas de inserção no mercado de trabalho, os assistidos manifestaram esperança na criação de novas oportunidades de trabalho, tendo em vista as inserções temporárias de trabalho, mas também revelaram desestímulo por força de questões como a falta de carteira assinada e a sua desqualificação profissional.

Os resultados obtidos possibilitam o alcance do objetivo proposto nesta pesquisa de se conhecer as representações sociais do trabalho para assistidos do sistema penitenciário cearense, suas formas de inserção e as expectativas em relação aos contextos de trabalho, isto é, de se compreender o que eles pensam sobre o trabalho, permitindo identificar que as representações sociais partilhadas pelos assistidos são, principalmente, objetivadas no modelo trabalhador-cidadão, que aparentemente se encontra fortemente ancorado no modelo motivacional, neoliberal.

Identificou-se, ainda, por um lado, alguns aspectos que dificultam o processo de participação dos assistidos do sistema penitenciário no mercado de trabalho e, por outro, destacou-se a importância do desenvolvimento de novos estudos que contemplem outros questionamentos e que investiguem amostras diferentes envolvidas com essa problemática, sugerindo-se, por pertinente, a temática do preconceito em relação ao egresso do sistema prisional pela fundamentação da teoria das representações sociais.

Por fim, conclui-se que uma mudança no trabalho no sistema penitenciário é importante, mas que não pode vir senão atrelada a uma mudança na sociedade e nos seus modos de receber e lidar com os egressos.

\section{Referências}

Abric, J.-C. (1994). Pratiques sociales et représentations. Presses Universitaires de France.

Barbalho, L. A., \& Barros, V. A. (2010). O lugar do trabalho na vida do egresso do sistema prisional: Um estudo de caso. Gerais: Revista Interinstitucional de Psicologia, 3(2), 198-212.

Bardin, L. (2010). Análise de conteúdo. Edições 70. (Trabalho original publicado em 1977). 
Barros, V. B. (2009). O trabalho na contemporaneidade: delimitações em um mundo de exclusão. In F. K. Neto, R. T. Oliveira, \& R. O. Silva (Orgs.), Subjetividade (s) e sociedade: contribuições da Psicologia (pp. 143-160). Conselho Regional de Psicologia de Minas Gerais.

Bauer, M. W., \& Gaskell, G. (2017). Pesquisa qualitativa com texto, imagem e som: um manual prático. Editora Vozes Limitada.

Bernal, A. O. (2010). Psicologia do trabalho em um mundo globalizado: como enfrentar o assédio psicológico e o estresse no trabalho. Porto Alegre: Artmed. Bussinguer, M. D. A. (2013). Política pública e inclusão social: o papel do direito do trabalho. LTr.

Cardoso, M. C. V. (2006). A cidadania no contexto da Lei de Execução Penal: o (des) caminho da inclusão social do apenado no Sistema Penitenciário do Distrito Federal (Dissertação de Mestrado). Universidade de Brasília, Brasília, Distrito Federal, Brasil. http://repositorio.unb.br/bitstream/104 82/4990/1/2006_Maria\%20Cristina\%20Vida1\%20Cardoso.pdf

Coimbra, C. M. B. (2001, janeiro/junho). Psicologia, direitos humanos e neoliberalismo. Revista Psicologia Política, 1(1), 139-148.

Conselho Nacional de Justiça (CNJ). (2014). Falhas na gestão dos processos contribuem para a superpopulação carcerária, diz conselheiro do CNJ. Recuperado de http://www.cnj.jus.br/noticias/cnj/61364-falhas-na-gestao-dos-processos-contribuem-para-a-superpopulacao-carceraria-diz-conselheiro-do-cnj

Esteban, F., Alós, R., Jódar, P., \& Miguélez, F. (2014). La inserción laboral de ex reclusos. Una Aproximación cualitativa. Revista Española de Investigaciones Sociológicas, 145, 181-204. https://doi.org/10.5477/cis/reis.145.181

Jacques, M. G. (1997). Identidade e trabalho. In A. D. Cattani (Org.), Trabalho e tecnologia: dicionário crítico (pp. 127-131). Vozes.

Julião, E. F. (2010). O impacto da educação e do trabalho como programas de reinserção social na política de execução penal do Rio de Janeiro. Revista Brasileira de Educação, 15(45), 529-543. https://doi.org/10.1590/S1413-24782010000300010

Lemos, A. M., Mazzilli, C., \& Klering, L. R. (1998, setembro/dezembro). Análise do Trabalho Prisional: Um Estudo Exploratório. Rev. Adm. Contemp., Curitiba, 2(3), 129-149. http://dx.doi.org/10.1590/S1415-65551998000300008

Lopes, P. L., Gregorio, M. F. P., \& Accioly, T. C. O. (2016). A inserção de egressos no mercado de trabalho. Revista Conbrad, Maringá, 1(1), 47-70.

Madeira, L. M. (2008). Trajetórias de Homens Infames: Políticas Públicas Penais e Programas de Apoio a Egressos do Sistema Penitenciário no Brasil (Tese de Doutorado). Universidade Federal do Rio Grande do Sul, Porto Alegre, Rio Grande do Sul, Brasil. http://www.lume.ufrgs.br/handle/10183/15656

Medeiros, L. F. R., \& Macêdo, K. B. (2006, maio/agosto). Catador de material reciclável: uma profissão para além da sobrevivência? Psicologia \& Sociedade, $18(2), 62-71$.

Medina, C. A. (1977). Participação e trabalho social: um manual de promoção humana. Vozes.

Moki, M. P. (2005). Representações Sociais do Trabalho Carcerário Feminino (Dissertação de Mestrado). Universidade Federal de São Carlos, São Carlos, Brasil.

Navarro, V. L., \& Padilha, V. (2007). Dilemas do trabalho no capitalismo contemporâneo. Revista Psicologia \& Sociedade, 19(1), 14-20.

Moscovici, S. (2010). Representações Sociais: investigações em Psicologia Social. Vozes.

Salanova, M., Gracia, F., \& Peiró, J. M. (1996). Significado del Trabajo y valores laborales. In J. M. Peiró, \& F. Prieto (Eds.), Tratado de Psicología del Trabajo (Vol. II: Aspectos psicosociales del trabajo, pp. 35-63). Síntesis.

Sampaio, J. H. (2008). Os direitos fundamentais e garantias individuais como pressupostos para a eficácia dos direitos humanos do presidiário (Dissertação de Mestrado). Universidade de Fortaleza, Fortaleza, Ceará, Brasil. http://bdtd.ibict.br/ vufind/Record/UFOR_237db5ecdb1f7f078a487dbd5c442591

Rocha, V. F. T., Lima, T. C. B., Ferraz, S. F. S., \& Ferraz, S. B. (2013). A inserção do egresso prisional no mercado de trabalho cearense. Pensamentos Contemporâneo em Administração, Rio de Janeiro, 7(4), 185-207.

Santos, T. M., \& Rosenburg, E. G. (2014). Representações sociais sobre a violência em egressos do sistema prisional. Segurança Pública, 8(1), 94-110.

Seron, P. C. (2009). Nos difíceis caminhos da liberdade: estudo sobre o papel do trabalho na vida de egressos do sistema prisional (Dissertação de Mestrado). Universidade de São Paulo, São Paulo, São Paulo, Brasil.

Souza, C. (2007). Estado da arte da pesquisa em políticas públicas. In G. Hochman, M. Arretche, \& E. Marques (Orgs.), Políticas públicas no Brasil (pp. 6586). Rio de Janeiro: Fiocruz.

Souza, S. A. (2009). Coletivos de Trabalhos e o Prazer e o Sofrimento em sua Construção: um estudo de caso (Dissertação de Mestrado). Universidade Federal de Itajubá, Itajubá, Minas Gerais, Brasil.

Toledo, I. d’A., Kemp, V. H., Machado, M. N. M. (2014). Os sentidos do trabalho para egressos do sistema prisional inseridos no mercado formal de trabalho. Cadernos de Psicologia Social do Trabalho, 17(1), 85-99. 10.11606/issn.1981-.0490.v17n1p85-99

Tomé, S. M. G. (2011). O Processo de Reinserção Social de Apenados: Uma Análise Comparativa de Trajetórias de Vida (Dissertação de Mestrado). Universidade Federal de Viçosa, Minas Gerais, Brasil.

Vala, J. (2002). Representações sociais e psicologia social do conhecimento cotidiano. In J. Vala, \& J. M. B. Monteiro (Coords.), Psicologia Social (pp. 457502). Lisboa: Fundação Calouste Gulbenkian. 